RAEIC, Revista de la Asociación Española de Investigación

\title{
Comunicação em Saúde: a cobertura mediática e a gestão da crise COVID-19 numa universidade
}

Health Communication: the media coverage and the COVID-19 crisis management at the university

Ruão, Teresa

Universidade do Minho (UMinho)

truao@ics.uminho.pt

Gomes, Sofia

Universidade do Minho (UMinho)

emilianasofiagomes@gmail.com

Silva, Sónia

Universidade do Minho (UMinho)

sonia.c.melo.silva@gmail.com

Forma de citar este artículo:

Ruão, T., Gomes, S. y Silva, S. (2020). “Comunicação em Saúde: a cobertura mediática e a gestão da crise COVID-19 numa universidade", RAEIC, Revista de la Asociación Española de Investigación de la Comunicación, vol. 7, núm. 14, 54-77.

https://doi.org/10.24137/raeic.7.14.3

RAEIC, Revista de la Asociación Española de Investigación de la Comunicación vol. 7, núm. 14 (2020), 54-77 


\section{Resumo:}

Em Março deste ano, Portugal encerrava a primeira instituição de ensino superior do país no contexto da pandemia de COVID-19. Os média cobriam exaustivamente o assunto, enquanto a Universidade do Minho (UMinho) iniciava os protocolos de gestão de crise. Neste trabalho, analisamos a cobertura mediática desta universidade e a sua estratégia de comunicação, como pretexto para refletir sobre os processos de produção noticiosa em situações de crise de saúde pública.

O estudo de caso foi a metodologia usada para olhar este fenómeno, com recurso ao método da análise documental (qualitativa e quantitativa) que permitiu tratar e interpretar os dados. Foram analisados os artigos noticiosos de seis meios - Público, Jornal de Notícias, Diário do Minho, Correio do Minho, ComUM e RUM- e as peças de comunicação tornadas públicas pela Universidade.

A análise mostrou um alinhamento entre a cobertura noticiosa e as mensagens da UMinho. Trata-se de um procedimento referido nos manuais de "boas práticas" da comunicação de crise, mas que que levanta preocupações cívicas. A qualidade da informação no espaço público depende do alinhamento dos atores envolvidos no processo noticioso, ou do debate e do exercício do contraditório? Eis uma discussão que deveria aproximar os campos do Jornalismo e da Comunicação Estratégica.

Palavras-chave: Comunicação em Saúde, Comunicação de Crise, Comunicação Estratégica, Jornalismo de Saúde, COVID-19.

\section{Abstract:}

In March this year, Portugal closed the first higher education institution in the context of the COVID-19 pandemic. The media covered the topic exhaustively, while the University of Minho (UMinho) started the crisis management protocols. This study analysis the UMinho media coverage and its communication strategy, as a pretext to reflect on the processes of news production in public health crisis. 
The case study was the methodology selected to look at this phenomenon, using document analysis (qualitative and quantitative) as main data gathering method. News from six media -Público, Jornal de Notícias, Diário do Minho, Correio do Minho, ComUM and RUM- and the communication messages made public by the University were collected and examined.

The research showed an alignment between the news coverage and the UMinho messages. This is a phenomenon mentioned in the 'best practices' of crisis communication, but it raises some concerns. Does the information quality in the public space rely on the alignment of the actors involved in the news process or on the debate and the exercise of the contradictory? Here is a discussion that should bring together the fields of Journalism and Strategic Communication.

Keywords: Health Communication, Crisis Communication, Strategic Communication, Health Journalism, COVID-19.

\section{INTRODUÇÃO}

Em Março de 2020, Portugal encerrava as primeiras instituições de ensino no país onde tinham sido detetados casos de COVID-19. Os média cobriam exaustivamente o assunto, enquanto as populações se sentiam cada vez mais indefesas perante um inimigo desconhecido. Este estudo analisou a cobertura mediática de uma universidade Portuguesa no contexto da pandemia de COVID-19 e a sua estratégia de comunicação de crise, como pretexto para refletir sobre os processos de produção noticiosa em situações de crise de saúde pública.

COVID-19 foi o nome atribuído pela Organização Mundial da Saúde à doença ${ }^{1}$ provocada pelo SARS-CoV-2, um novo coronavírus. Identificada pela primeira vez em dezembro de 2019, em Wuhan, as suas fontes de infeção e transmissão ainda são desconhecidas. Contudo, os primeiros casos de COVID-19 estão associados ao mercado Wuhan's Huanan Seafood Wholesale. Apesar do espaço ter sido encerrado a 1 de janeiro de 2020, não foi

\footnotetext{
${ }^{1}$ Os sintomas da COVID-19 podem ser febre, tosse, dor de garganta, cansaço e dores musculares e, em casos mais graves, pneumonia grave, síndrome respiratória aguda grave, septicémia, choque sético e eventual morte. Os sinais de doença variam em função da gravidade e há casos de ausência total de sintomas (assintomáticos).
} 
possível travar a progressão da doença que desencadeou uma epidemia mundial ou pandemia ${ }^{2}$. Em poucos meses, afetou mais de 180 países (Valero-Cedeño, Mina-Ortiz, VelizCastro, Merchán-Villafuerte e Perozo-Mena, 2020).

Neste quadro de crise de saúde pública, os média assumiram um papel essencial no processo de prestação de informação atualizada às populações, um pouco por todo o mundo. Tornaram-se fontes primárias de informação e importantes líderes de opinião, influenciando o comportamento individual e comunitário. A atenção e tempo dedicados à cobertura noticiosa em saúde cresceu exponencialmente. Por outro lado, cresceram também as atividades de assessoria de imprensa de instituições públicas de saúde, e outras, destinadas a preparar e enviar pacotes de informação aos média, com o propósito de chegar às populações. A importância e urgência desta informação potenciou o trabalho conjunto destes dois atores públicos, num esforço humanitário global. Mas em que medida este alinhamento entre as organizações públicas e os média favorece a "qualidade" (Lacy e Rosenstiel, 2015) da informação no espaço público? Estarão os jornalistas e as organizações a produzir informação transparente para capacitar os cidadãos a tomarem as melhores decisões em saúde, no quadro da pandemia de COVID-19?

O estudo da relação entre os média e as instituições-fontes constitui um tema muito explorado no campo da Comunicação em Saúde, uma disciplina científica que emergiu na década de 80 (Kreps e Thornton, 1984; Sharf, 1984; Northouse e Northouse, 1985). A Comunicação em Saúde dedica-se ao "estudo e uso de métodos que permitem influenciar as decisões individuais e grupais de modo a melhorar a saúde dos cidadãos" (Freimuth e Quinn, 2004, p. 2053). Assim, uma das preocupações deste campo é a compreensão da influência da comunicação humana mediada na prestação e promoção de cuidados de saúde às populações. E é neste quadro que encontramos interesses convergentes dos campos do Jornalismo e da Comunicação Organizacional Estratégica.

Neste estudo, pretendemos analisar a relação entre o trabalho dos jornalistas e o trabalho das assessorias de comunicação no contexto da disseminação de informação relativa à

\footnotetext{
2 Uma pandemia é entendida como uma enfermidade que resulta de um surto repentino, com rápida difusão (Vaughan e Tinker, 2009).
} 
COVID-19 em Portugal, a partir da análise dos artigos noticiosos e da comunicação levada a cabo por uma universidade Portuguesa. Para realizar este estudo, e conferindo às instituições públicas um papel de maior responsabilidade na gestão de crise e promoção da informação pública de qualidade (na linha do pensamento de Selznick, 1996), selecionámos o caso da UMinho.

\section{REFERENCIAL TEÓRICO}

\subsection{O JORNALISMO DE SAÚDE}

Vivemos num ambiente global de valorização e partilha acelerada da informação, que inclui cada vez mais os temas da saúde em resultado do seu crescente interesse social e político. Neste quadro, os média foram assumindo o papel de importantes fornecedores de informação sobre saúde às populações, chamando a si uma função de enorme responsabilidade social (Mena-Young, 2020; Thomas e Senkpeni, 2020; Casero-Ripollés, 2020; Calvo, 2017).

O caso particular da mediatização da COVID-19 mostra isto mesmo. Em contextos como este, a informação mediática pode ser uma ferramenta muito importante para reduzir as dúvidas e a ansiedade da população, constituindo-se como um pilar orientador, quando assente em fontes credíveis e factos científicos (Casero-Ripollés, 2020; Thomas e Senkpeni, 2020). Como referem Lázaro-Rodríguez e Herrera-Viedma (2020, p. 3), "em situações de alerta geral causadas por pandemias, terramotos ou atentados terroristas, aumenta 0 interesse por informação e por notícias sobre os ditos acontecimentos". Este interesse da audiência resulta, concomitantemente, num aumento do espaço que os média dedicam ao assunto (Costa-Sánchez e López-García, 2020). O público é um elemento fundamental no processo de produção noticiosa. E o Jornalismo constitui um modo de exercício da cidadania (Casero-Ripollés, 2020; Kovach e Rosenstiel, 2007) e de "capacitação para uma prática mais sustentada de participação cívica" (Martins, 2010, p. 9).

Mas convém referir que o efeito da intensa cobertura de um assunto, como uma pandemia, também pode ser o contrário ao pretendido e resultar em alarmismo social (Costa-Sánchez e López-García, 2020). Apesar deste crescente interesse por notícias de saúde, fatores externos ao Jornalismo - como a escassez de recursos humanos, dificuldades económicas ou exigências concorrenciais - condicionam o desempenho dos jornalistas. A carga de 
trabalho destes profissionais tem aumentado, mas o tempo, o espaço e os recursos para trabalho de campo tendem a diminuir (Schwitzer, 2009; Wilson et al., 2010).

Além do mais, outros determinantes da produção noticiosa entram em cena, como a relação com as fontes. Trata-se de atores individuais ou organizacionais que podem ter marcados interesses próprios no acesso aos média. Os jornalistas selecionam e divulgam o conhecimento produzido em diferentes áreas da realidade social, desempenhando o papel de gatekeepers (Obregón, 1998, Gomes, 2019; Kovach e Rosenstiel, 2003; White, 1950). As fontes de informação procuram influenciar a agenda mediática para, assim, criarem esquemas de interpretação social que corroborem os seus interesses (Lopes, Ruão, Marinho e Araújo, 2011a). E desta interação resulta a informação disponibilizada ao público.

Estudos realizados em Portugal sobre a cobertura jornalística de assuntos de saúde apontam para a proatividade de algumas fontes nesta área e para o seu enorme poder "de especialistas". Estes factos, se associados à falta de recursos do jornalismo e à preferência por fontes geograficamente próximas e com competências comunicativas relevantes, conduzem a uma reduzida diversidade de fontes de informação nos textos noticiosos deste campo específico. Esta situação parece reforçar a existência de elites de poder e de fontes deixadas à margem e no silêncio, assim como robustece o papel das assessorias de imprensa na produção noticiosa em saúde (Lopes, 2007; Lopes et al., 2011a; Ruão, Lopes, Marinho e Araújo, 2011).

Mas a mediatização da COVID-19 parece ter caraterísticas particulares. Estudos recentes apontam, por exemplo, para uma mudança no que diz respeito à audiência e às fontes. Cidadãos habitualmente menos interessados na informação mediática -como os mais jovens e pessoas com menor grau de instrução- aumentaram o seu consumo de notícias face à pandemia (Casero-Ripollés, 2020) e o valor da informação científica ganhou especial reconhecimento enquanto fonte de conhecimentos sobre a COVID-19 (Lázaro-Rodriguez e Herrera, 2020). Em Portugal, onde anteriormente se registava uma tendência para não publicar textos noticiosos associados a doenças (Lopes et al., 2011a), a situação alterou-se exponencialmente nos últimos meses (Marktest, 03/2020). Em suma, a cobertura noticiosa em situação de crise parece alterar os padrões conhecidos e fazer emergir uma nova realidade, numa equação também marcada pelo comportamento das fontes. 


\subsection{COMUNICAÇÃO DE CRISE}

Entendemos a Comunicação Estratégica como toda a comunicação planeada de modo sistemático para produzir efeitos persuasivos nas ideias, atitudes e comportamentos dos públicos (Hallahan, Holtzhausen, Van Ruler, Verčič, e Sriramesh, 2007). E propomos a Comunicação de Crise como um tipo de comunicação estratégica aplicada às situações de emergência ou catástrofe (na linha de Coombs, 2015).

A Comunicação de Crise é uma área do conhecimento e um campo de exercício profissional que compreende um conjunto de ações de comunicação destinadas a gerir uma situação de crise, incluindo a recolha, o processamento e a disseminação de informação, através de equipas especializadas, que preparam planos de comunicação para garantir a transmissão adequada das mensagens aos diversos públicos (Coombs, 2007, 2010, 2015). A Comunicação de Crise é ativada sempre que a organização enfrenta algum tipo de acontecimento que a coloca num cenário de incerteza e ameaça, perante o qual é necessário promover a mudança de atitudes e comportamentos dos seus membros, ao mesmo tempo que é preciso defender estrategicamente a posição adotada (Herman, 1963; Reynolds e Seeger, 2005).

No âmbito das estratégias de Comunicação de Crise, destaca-se o estabelecimento de relações com os média. Quando se deparam com uma situação de emergência, as organizações precisam de defender a sua posição, evitando que outras entidades assumam o papel de fontes oficiais nas notícias que são publicadas sobre si (Coombs, 2007; Ray, 1999). Nesta tentativa de controlar a informação, cabe aos responsáveis de comunicação definirem planos de assessoria de imprensa que se alinhem com o processo de produção jornalística, privilegiando os conteúdos com características noticiáveis (Holladay, 2009). Como referiu Mcquail (2003), esta relação alinhada entre jornalistas e fontes é essencial para a preparação da notícia.

No contexto de uma crise de saúde comunitária, as instituições públicas assumem um papel de relevo na prevenção e mitigação da doença, mediante o envio de mensagens que incentivam a população a adotar comportamentos de segurança (Vos e Buckner, 2016). Essas mensagens de prevenção ou reparação devem ser oriundas das autoridades de saúde, mas a sua eficácia depende do envolvimento de outras organizações públicas. Segundo 
Ruão et al. (2012), os organismos públicos têm a tarefa de proteger e melhorar a saúde pública e a sua cooperação e coordenação são fundamentais para lidar com emergências, como o caso da pandemia da COVID-19. Trata-se de um círculo de responsabilidades de que fazem parte igualmente os média, pois, de acordo com as melhores práticas da Comunicação de Crise em saúde, as mensagens de prevenção/reparação devem ser enviadas através de canais familiares à população como é o caso da televisão, da rádio, dos jornais (impresso e online) e, mais recentemente, dos médias sociais (Lopes, Ruão, Marinho e Araújo, 2012; Ruão et al., 2011; Costa-Sánchez e López-García, 2020). E é esta relação entre entidades públicas e os meios de comunicação social em cenários de crise de saúde pública que exploramos neste estudo.

\section{O CASO DA UNIVERSIDADE DO MINHO}

A 30 de janeiro de 2020, a Organização Mundial de Saúde (OMS) declarou uma situação de Emergência de Saúde Pública de Âmbito Internacional em virtude da expansão da COVID19. Em Portugal, a 7 de março, em conferência de imprensa, a Ministra da Saúde avançou com a notícia do "encerramento de algumas escolas e instituições... devido ao surto de coronavírus", entre as quais "o edifício do curso de História da Universidade do Minho" ${ }^{3}$. Dias mais tarde, a 11 de março, a OMS considerou o surto de COVID-19 como uma pandemia.

Já antes de ser identificado um caso de COVID-19 na comunidade académica, o reitor da UMinho respondeu às recomendações da Organização Mundial de Saúde e da Direção-Geral da Saúde de Portugal e nomeou uma Comissão de Elaboração e Gestão do Plano de Contingência Interno COVID-19 (3 de março). Esta comissão de crise incluía especialistas em saúde, a administração da universidade e representantes dos vários serviços, funcionários e alunos, tendo sido mais tarde alargada para incluir um especialista em comunicação (14 de abril $)^{4}$.

Após a associação de um doente COVID-19 à UMinho e das declarações da Ministra da Saúde, a atividade da instituição sofreu várias restrições, resultantes da necessidade de

\footnotetext{
${ }^{3}$ https://sicnoticias.pt/especiais/coronavirus/2020-03-07-Covid-19-Governo-anuncia-encerramento-dealgumas-escolas-e-instituicoes

${ }^{4}$ https://www.uminho.pt/PT/viver/COVID-19/Documents/Despacho RT 40-2020 PT.pdf, acedido a 04 de junho de 2020
} 
adequação do funcionamento da Universidade ao contexto da pandemia. De entre essas medidas, destaca-se a suspensão das atividades letivas presenciais e a adoção do regime de teletrabalho.

A UMinho foi fundada em 1973, tem cerca de 20 mil alunos, está distribuída por dois campi (nas cidades de Braga e Guimarães) e é, atualmente, uma fundação pública de direito privado, ao abrigo do Regime Jurídico das Instituições de Ensino Superior. A UMinho dispõe de um Gabinete de Comunicação e Imagem que coopera com a Reitoria "na definição de políticas e estratégias de Comunicação e Imagem", garantindo "o contacto com os meios de comunicação social”" ${ }^{\prime}$.

\section{METODOLOGIA}

De modo a delimitarmos o nosso campo de estudo, foi definida a seguinte questão de partida: em que medida o alinhamento comunicativo entre as organizações públicas e os média favorece a qualidade da informação prestada, no contexto de uma crise de saúde pública?

A questão do "alinhamento" da comunicação é um tema amplamente estudado no campo da Comunicação Estratégica e sugere-se que a adaptação ou o alinhamento da estratégia de uma organização com o seu contexto é fundamental para reagir a oportunidades e ameaças ambientais (Walter, Kellermanns, Floyd, Veiga e Matherne, 2013). Além disso, no contexto da Comunicação em Saúde, é possível encontrar evidências noutros estudos realizados, por exemplo, para analisar os surtos de gripe A (Lopes, Ruão e Marinho, 2010) e E.Coli (Lopes et al., 2011b) - de que o alinhamento da comunicação entre as autoridades de saúde e os média melhora a qualidade das informações fornecidas aos cidadãos e cria maior confiança junto do público. E entendemos o conceito de "qualidade" no Jornalismos a partir de uma das aceções discutidas por Lacy e Rosenstiel (2015): como a capacidade de fornecer informação útil aos cidadãos para que tomem melhores decisões e sejam capazes de se proteger contra o abuso de poder e as más práticas públicas.

Para olhar precisamente estes fenómenos, escolhemos como metodologia de investigação o estudo de caso. Trata-se de uma abordagem com tradição nos estudos de Jornalismo

\footnotetext{
${ }^{5}$ https://www.uminho.pt/PT/uminho/Unidades/Servicos, acedido a 16 de abril de 2020
} 
(Atton, e Wickenden, 2005), no campo da Comunicação de Crise (Coombs, 2007) e na pesquisa sobre o ensino superior (Ruão, 2008). O estudo de caso é particularmente adequado quando o foco é a análise de um fenómeno contemporâneo em contexto real e quando o fim da investigação é essencialmente exploratório e interpretativo e não se destina à confirmação de dados (Yin, 2014).

Foi realizado assim um estudo de caso único, à UMinho. A escolha desta instituição, como exemplo-tipo (Yin, 2014), teve por base as seguintes considerações: esta instituição foi a primeira universidade Portuguesa a encerrar para prevenir um surto da doença e foi a primeira a ativar os protocolos de gestão de crise, incluindo ações de comunicação com os média. Acresce ainda ter-se tratado de uma seleção por conveniência, já que é instituição de acolhimento das investigadoras, permitindo isso uma recolha de dados mais rápida pelo acesso facilitado.

O estudo de caso assentou na técnica da análise documental, através da qual foram examinadas as notícias divulgadas sobre a instituição em jornais nacionais, regionais e locais, bem como os documentos -escritos, audiovisuais e multimédia- produzidos e disseminados pela UMinho. Estes documentos foram explorados através da análise de conteúdo (Bardin, 2011; Schreier, 2012), quantitativa (no caso das notícias publicadas pelos média) e qualitativa (no caso dos documentos institucionais).

Para estudar a cobertura jornalística, selecionamos seis publicações com edição online: o Público e o Jornal de Notícias (nacionais), o Diário do Minho e o Correio do Minho (regionais), - ComUM e a RUM (ligados à UMinho). Procurou-se, assim, diversidade editorial e geográfica para perceber se essas variáveis afetavam o tratamento noticioso dado à informação da Universidade. Nos sites destes meios de comunicação foram pesquisadas as seguintes palavras-chave: COVID-19, Coronavírus, Universidade do Minho e UMinho, sendo a pesquisa limitada aos artigos noticiosos publicados no período de um mês. Foram, portanto, trabalhadas todas as publicações resultantes desta pesquisa, podendo o seu formato variar entre notícias, entrevistas, programas de rádio, infografias, entre outras possibilidades.

Estando assim selecionados os textos, optou-se por uma análise quantitativa dos dados, através de uma estatística descritiva univariada, tendo por base as seguintes variáveis: 
assunto, tipo de conteúdo, fonte, autoria do texto, tempo da escrita, bem como o evento (em caso de existência) que motivou a notícia.

Quanto à informação produzida pela organização, foram analisadas todas as comunicações oficiais da Universidade, incluindo despachos oficiais, comunicados à imprensa, comunicados internos ou vídeos institucionais. Como categorias de análise definiram-se: os canais de comunicação utilizados, o tipo de conteúdo ou o acontecimento noticiável, o porta-voz (quando existente), o assunto e o eixo da mensagem.

O período considerado para a recolha de dados foi de um mês e teve como referência a data da confirmação do primeiro caso de COVID-19 na UMinho, ou seja, o intervalo entre 7 de março e 7 de abril de 2020. Uma vez que o fim desta pandemia é ainda desconhecido, e face à impossibilidade de acompanhar toda a sua evolução, optou-se por analisar a mediatização da primeira fase de resposta da UMinho à pandemia provocada pela COVID-19.

\section{APRESENTAÇÃO E DISCUSSÃO DOS DADOS}

Da exploração inicial do corpus de análise selecionado, resultou um conjunto de dados que organizamos em função da data da sua emissão/publicação. Depois de uma recolha isolada, que teve início com a análise dos textos noticiosos e prosseguiu com a pesquisa da fonte, os dados foram ordenados numa tabela única (tabela 1) para permitir perceber o alinhamento da cobertura mediática e aferir se este tinha tido origem no comportamento da instituição.

Tabela 1. Cruzamento entre as ações de assessoria e imprensa e a cobertura noticiosa.

\begin{tabular}{|c|c|}
\hline \multicolumn{2}{|c|}{ Comportamento / Comunicação dos Atores Públicos em situação de Crise } \\
\hline Comunicação da UMinho & Cobertura nos média \\
\hline $\begin{array}{l}7 \text { de março } \\
\text { Conferência de imprensa na DGS } \\
\text { Despacho RT-23/2020 } \\
\text { - Decretado o encerramento de um edifício na } \\
\text { UMinho } \\
\text { - Confirmação interna do primeiro caso de } \\
\text { Covid-19 } \\
\text { - Suspensão das atividades letivas e de vários } \\
\text { serviços no campus de Braga } \\
\text { - Recomendação de quarentena profilática }\end{array}$ & $\begin{array}{l}7 \text { de março } \\
\text { - CM: "UMinho confirma caso de covid-19 e } \\
\text { encerra campus de Gualtar" } \\
\text { - DM: “Covid-19 fecha campus de Gualtar da } \\
\text { UMinho" } \\
\text { - DM: “Edifício do departamento de História da } \\
\text { UMinho encerrado devido ao coronavírus" } \\
\text { - DM: “Campus fechado e } 180 \text { alunos } \\
\text { monitorizados na UMinho" } \\
\text { - ComUM: "Caso confirmado de COVID-19 leva ao } \\
\text { encerramento do ICS" } \\
\text { - ComUM: "Reitoria da Universidade do Minho } \\
\text { suspende atividades no Campus de Gualtar" } \\
\text { - RUM: "Edifício onde funciona curso de História da } \\
\text { UMinho encerrado" }\end{array}$ \\
\hline
\end{tabular}




\begin{tabular}{|c|c|}
\hline & $\begin{array}{l}\text { - RUM: “Caso confirmado suspende actividade } \\
\text { lectiva em Gualtar e fecha ICS" } \\
\text { - JN: “Coronavírus deixa a Região Norte em alerta } \\
\text { máximo" } \\
\text { - Público: “Universidade do Minho suspende aulas } \\
\text { em campus de Braga" }\end{array}$ \\
\hline $\begin{array}{l}8 \text { de março } \\
\text { Despacho RT-24/2020 } \\
\text { Comunicado 01/2020 } \\
\text { - Encerramento de todas as atividades no } \\
\text { campus de Braga } \\
\text { - Adoção do teletrabalho nas unidades } \\
\text { encerradas } \\
\text { - Recomendação de quarentena profilática aos } \\
\text { estudantes das residências }\end{array}$ & 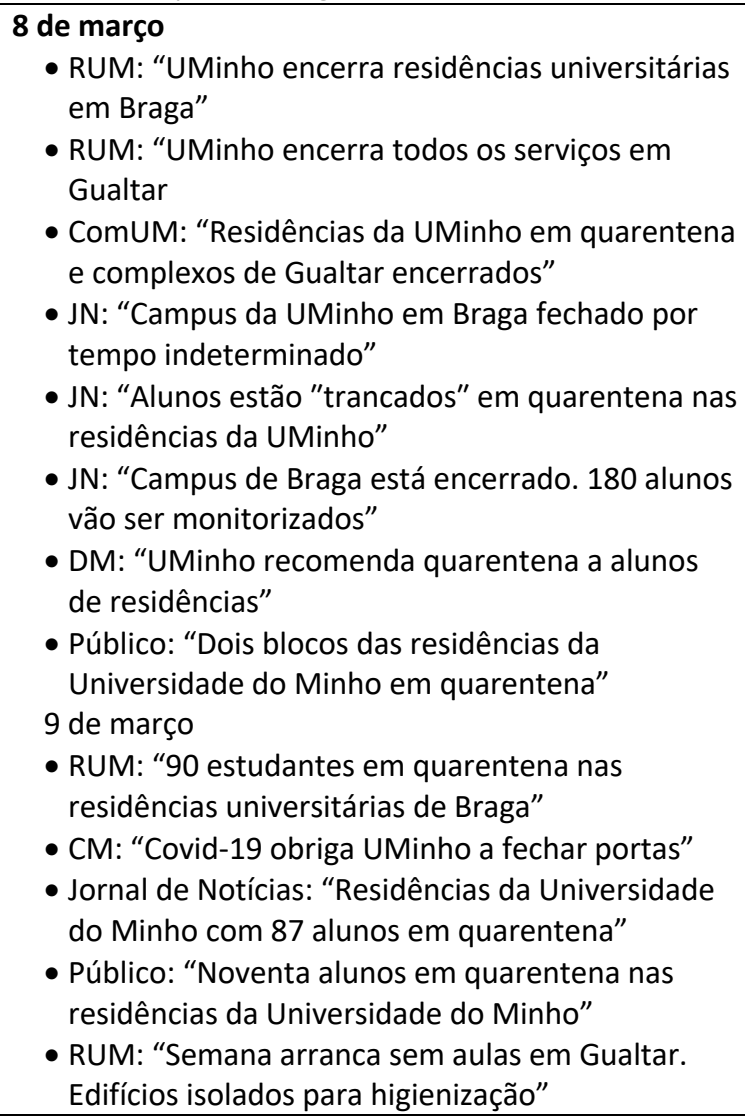 \\
\hline $\begin{array}{l}9 \text { de março } \\
\text { Publicação nas redes sociais } \\
\text { - Adiamento de feira de divulgação de oferta } \\
\text { formativa }\end{array}$ & $\begin{array}{l}9 \text { de março: } \\
\text { - ComUM: "Atividade Universidade Portas Abertas } \\
\text { adiada" } \\
10 \text { de março: } \\
\text { - RUM: "UMinho adia actividade 'Universidade de } \\
\text { Portas Abertas'” }\end{array}$ \\
\hline $\begin{array}{l}10 \text { de março } \\
\text { Despacho RT-25/2020 } \\
\text { - Suspensão das atividades presenciais em toda } \\
\text { a UMinho } \\
\text { - Instituição formal do teletrabalho e do ensino } \\
\text { à distância }\end{array}$ & $\begin{array}{l}10 \text { de março: } \\
\text { - DM: “UMinho alarga suspensão de aulas a toda a } \\
\text { universidade" } \\
\text { - JN: “Aulas suspensas em toda a Universidade do } \\
\text { Minho" } \\
\text { - RUM: "UMinho suspende todas as aulas } \\
\text { presenciais" } \\
\text { - ComUM: “Atividades interrompidas em toda a } \\
\text { Universidade do Minho" } \\
\text { 11 de março: } \\
\text { - CM: "Universidade do Minho alarga suspensão ao } \\
\text { pólo de Guimarães" }\end{array}$ \\
\hline $\begin{array}{l}15 \text { de março } \\
\text { Publicação no website e redes sociais } \\
\text { - Lançamento do Centro de Medicina P5, } \\
\text { plataforma da Escola de Medicina para dar } \\
\text { resposta a dúvidas sobre a COVID-19 }\end{array}$ & $\begin{array}{l}16 \text { de março: } \\
\text { - RUM: "Escola de Medicina da UMinho oferece } \\
\text { plataforma de serviços clínicos digitais" } \\
19 \text { de março: } \\
\text { - CM: "Escola de Medicina na linha da frente" }\end{array}$ \\
\hline
\end{tabular}




\begin{tabular}{|c|c|}
\hline $\begin{array}{l}17 \text { de março } \\
\text { Declaração do Reitor (vídeo) } \\
\text { - Agradecimento do reitor à comunidade } \\
\text { académica e balanço das medidas adotadas }\end{array}$ & $\begin{array}{l}18 \text { de março: } \\
\text { - RUM: "Reitor agradece à comunidade académica } \\
\text { o esforço em tempo de crise" }\end{array}$ \\
\hline $\begin{array}{l}17 \text { de março } \\
\text { Receção do Ministro da Ciência, Tecnologia e } \\
\text { Ensino Superior } \\
\text { - Destaque para a rápida adaptação da UMinho } \\
\text { ao ensino à distância }\end{array}$ & Sem projeção nos média em estudo. \\
\hline $\begin{array}{l}24 \text { de março } \\
\text { Declaração do Reitor (vídeo) } \\
\text { - Esclarecimento sobre o modelo de avaliação a } \\
\text { adotar no ensino à distância }\end{array}$ & $\begin{array}{l}25 \text { de março: } \\
\text { • RUM: "UMinho pondera respostas às avaliações" }\end{array}$ \\
\hline $\begin{array}{l}30 \text { de março } \\
\text { Despacho RT-33/2020 } \\
\text { - Decretado o ensino à distância até ao } \\
\text { final do ano letivo }\end{array}$ & $\begin{array}{l}30 \text { de março: } \\
\text { - DM: “UMinho cumpre 2.o semestre com ensino à } \\
\text { distância e estende ano até } 27 \text { de junho" } \\
\text { - JN: “Universidade do Minho sem aulas até ao fim } \\
\text { do ano letivo" } \\
\text { - Público: "Universidade do Minho assume que não } \\
\text { haverá aulas até ao final do semestre" } \\
\text { - RUM: "UMinho determina ensino à distância até } \\
\text { ao fim do semestre" }\end{array}$ \\
\hline $\begin{array}{l}1 \text { de abril } \\
\text { Conferência de imprensa } \\
\text { - Lançamento da campanha para ajuda a } \\
\text { estudantes carenciados } \\
\text { - Definição do modelo para aulas práticas e } \\
\text { estágios }\end{array}$ & $\begin{array}{l}1 \text { de abril: } \\
\text { - DM: “Universidade do Minho vai garantir } \\
\text { computadores e Internet a alunos carenciados" } \\
\text { - JN: “UMinho ajuda alunos a comprar } \\
\text { computadores para aulas à distância” } \\
\text { - Público: "UMinho disponibiliza computadores e } \\
\text { acesso à Internet a alunos carenciados" } \\
\text { - RUM: "UMinho estuda modelo para aulas } \\
\text { práticas e estágios" } \\
\text { - RUM: "UMinho vai disponibilizar computadores e } \\
\text { internet para alunos carenciados" } \\
3 \text { de abril: } \\
\text { - JN: "Universidade do Minho apela ao donativo de } \\
\text { computadores para alunos carenciados" }\end{array}$ \\
\hline $\begin{array}{l}\text { de abril } \\
\text { Publicação nas Redes Sociais } \\
\text { - Projeto conjunto da UMinho e do Hospital de } \\
\text { Braga para a construção de ventiladores }\end{array}$ & $\begin{array}{l}4 \text { de abril: } \\
\text { - DM: “Hospital de Braga e UMinho têm novo } \\
\text { ventilador em fase de testes" }\end{array}$ \\
\hline $\begin{array}{l}6 \text { de abril } \\
\text { Publicação nas redes sociais } \\
\text { - Cedência de residência para utentes de lares } \\
\text { e instituições congéneres afetadas pela } \\
\text { COVID-19 }\end{array}$ & $\begin{array}{l}6 \text { de abril: } \\
\text { - DM: "UMinho disponibiliza residência } \\
\text { universitária para apoiar o combate contra a } \\
\text { COVID-19" }\end{array}$ \\
\hline
\end{tabular}

RAEIC, Revista de la Asociación Española de Investigación de la Comunicación vol. 7, núm. 14 (2020), 54-77 


\subsection{A COBERTURA MEDIÁTICA DA COVID-19 NA UMINHO}

A recolha dos textos dos seis meios noticiosos trabalhados neste estudo -entre os dias 7 de março e 7 de abril de 2020-, resultou num corpus de 91 artigos noticiosos.

Tabela 2. Distribuição do número de textos por meio noticioso.

\begin{tabular}{|c|c|}
\hline Meio noticioso & No de textos \\
\hline RUM & 32 \\
\hline Jornal de Notícias & 21 \\
\hline Diário do Minho & 12 \\
\hline ComUM & 10 \\
\hline Público & 9 \\
\hline Correio do Minho & 7 \\
\hline
\end{tabular}

Observando a distribuição dos textos por meio noticioso, constatamos que a RUM - Rádio Universitária do Minho foi o meio que mais publicou informação sobre a COVID-19 na UMinho. Vários são os fatores que podem estar na origem destes resultados. A RUM, por ser um órgão de comunicação diretamente ligado à UMinho, teve a vantagem da proximidade geográfica, assim como a de uma boa relação com os porta-vozes da Universidade, nomeadamente o reitor e o presidente da Associação Académica (AAUM). Adicionamos a estes aspetos, o facto de muitos jornalistas da RUM serem antigos alunos da UMinho e antigos colaboradores da AAUM. Note-se que também na cobertura Público encontramos este fator da proximidade com a instituição, apesar de não ser um meio com um nível de publicações elevado. De facto, o jornalista que escreveu quase todos os textos do Público é, também ele, um antigo estudante desta Universidade e do próprio Instituto onde se identificou o primeiro caso de COVID-19.

A proximidade geográfica é outra condicionante plausível e que pode explicar o segundo lugar do Jornal de Notícias relativamente a este caso. Mesmo sendo um meio nacional, tem sede no Porto e jornalistas dedicados à cobertura de acontecimentos na cidade de Braga. No que diz respeito à variável "meio noticioso", foi, por outro lado, surpreendente o reduzido número de artigos publicados pelos dois principais jornais da região: o Correio do Minho e o Diário do Minho. Questões relacionadas com as restrições da pandemia podem explicar estes valores. 
A análise ao conteúdo permitiu também perceber que há uma linha temporal seguida por praticamente todos os órgãos de comunicação estudados: a 7 de março, todos noticiam que a UMinho apresenta um caso de contaminação por COVID-19 e que encerra um dos seus edifícios, na sequência de afirmações da Ministra da Saúde. Uma informação que foi confirmada, mais tarde, pela Universidade através do despacho de um reitoral, que é citado por quase todos os meios noticiosos. O Correio do Minho faz mais do que citar o despacho, colocando-o na íntegra no corpo da notícia.

Depois disso, a 8 de março, também todos os meios publicam informação sobre o encerramento alargado de atividades e edifícios (conforme despacho oficial). Títulos como "UMinho recomenda quarentena a alunos de residências" (Diário do Minho, 8 de março), “Campus de Braga está encerrado. 180 alunos vão ser monitorizados" (Jornal de Notícias, 8 de março) ou "UMinho encerra residências universitárias" (RUM, 8 de março) surgem nos vários meios de comunicação social. Os meios mais próximos da universidade, como é o caso da RUM noticiaram, também, o encerramento voluntário de várias escolas da UMinho.

Esta linha temporal resulta da escolha dos despachos reitorais como fonte primordial. Por outras palavras, é possível dizer-se que a cobertura noticiosa da COVID-19 na UMinho foi, essencialmente, reativa, na medida em que grande parte dos textos constituiu precisamente uma reação à comunicação institucional da UMinho. De facto, nos 91 textos noticiosos analisados, foram identificadas 20 referências a despachos reitorais enquanto fontes de informação.

No que diz respeito ao conteúdo dos textos publicados, todos eles se fizeram acompanhar de fotografias, por vezes repetidas, o que sugere imagens de arquivo. No caso específico da $R U M$, por se tratar de uma rádio, muitos dos textos foram publicados por podcasts, protagonizados por fontes como o reitor e o presidente da Associação Académica.

O conteúdo das notícias sugere também que os textos foram maioritariamente escritos no presente $(64,8 \%)$. Esta informação contraria estudos anteriores que referiam uma tendência para os assuntos de saúde serem tratados no pretérito. A escrita no presente muito se justifica, neste estudo, pela rápida reação dos media aos despachos emitidos pelo reitor e ao grande número de textos publicados (sobretudo pela $R U M$ ) com a presença, quase em direto, das fontes. 
Precisamente no que diz respeito às fontes de informação, como já foi referido, os dados obtidos apontam para a presença dominante de despachos reitorais, ou seja, fontes documentais, seguindo-se o próprio reitor, o presidente da Associação Académica, a Ministra da Saúde e, pontualmente, presidentes de escolas da UMinho. Por outras palavras, foram ouvidas, fundamentalmente, fontes oficiais ou fontes especializadas que representam uma instituição. No que se refere ao reitor da UMinho, este transmitiu informação aos média, essencialmente, através de despachos, evidenciando-se ${ }^{6}$ a realização de apenas duas conferências de imprensa. Por sua vez, a AAUM comunicou, maioritariamente, por notas publicadas no seu website oficial, em detrimento do contacto direto com os jornalistas.

Contrariamente à forte presença destas fontes de informação, raras foram as vezes em que membros da sociedade foram chamados a dar o seu testemunho. Sobre estas fontes mantidas à margem, surge um facto curioso: três meios noticiosos publicaram reportagens sobre o impacto do encerramento da UMinho no comércio tradicional nas proximidades da instituição. O Jornal de Notícias foi o primeiro, tendo publicado, no dia 9 de março, uma reportagem com o título "Comerciantes apreensivos com suspensão de aulas na UMinho", seguindo-se a $R U M$, no dia 10 , com o texto "Comércio com queda de $80 \%$ na faturação depois do encerramento da UMinho" e o Correio do Minho, no dia 11, com a reportagem "Fecho da UMinho esvazia zona dos Peões". É, ainda, nestes três casos que se registam os poucos sinais de proatividade dos meios de comunicação analisados. Também um pouco à margem ficaram assuntos como investigações desenvolvidas por cientistas da UMinho, campanhas de solidariedade levadas a cabo pela comunidade académica, assim como o cancelamento de eventos cientifico-culturais.

\subsection{A ASSESSORIA DE IMPRENSA NA COMUNICAÇÃO DE CRISE DA UMINHO}

Tomando como referência esta leitura sobre a cobertura noticiosa, analisou-se a estratégia de comunicação de crise da Universidade, para perceber qual o papel da fonte, e os dados foram apresentados de modo combinado na tabela 1. Desses dados, concluímos haver um alinhamento entre as mensagens enviadas pela UMinho e a cobertura noticiosa que se gerou. A análise permitiu ainda perceber que este alinhamento resultou mais da atuação

\footnotetext{
${ }^{6}$ Importa referir que a análise aos artigos noticiosos é feita do ponto de vista do leitor.
} 
comunicativa da instituição do que da proatividade dos média. Ainda assim, ficou também manifesta a falta de planificação estratégica da comunicação de crise da Universidade, que foi reagindo aos acontecimentos sem segmentação de públicos, canais ou conteúdos.

A UMinho parece ter utilizado os mesmos canais e o mesmo tipo de conteúdo para comunicar com a comunidade universitária e com os públicos externos. Os conteúdos assumiram o formato de comunicados oficiais, declarações públicas e despachos formais. A instituição privilegiou a colocação dessa informação no website -onde criou a página COVID-197- e a partilha nas redes sociais. Embora, não sejam conteúdos ou canais de comunicação exclusiva com os média, as redes sociais são importantes fontes de informação para os jornalistas. A par da disponibilização pública deste material, as ações de assessoria de imprensa da UMinho também incluíram a realização de conferências de imprensa ou briefings curtos (após reuniões internas ou com as autoridades de saúde) e a divulgação de declarações oficiais do Reitor em vídeo, que assumiu, desde o início da crise, o papel de porta-voz. O eixo de mensagem foi a apresentação de uma instituição socialmente responsável e ativa no controlo e prevenção da pandemia, que privilegiou o bem-estar e a segurança de todos os seus membros internos e externos, encontrando o assunto uma ampla recetividade nos média locais e nacionais.

Ao escolher formatos de comunicação interna (claramente percetíveis no modelo dos comunicados, despachos e declarações em vídeos à academia) a serem enviados por meios de comunicação de audiências mistas (internas e externas), como o website e as redes, a Universidade não procedeu à segmentação de públicos. Contrariando, assim, um princípio defendido pelas melhores práticas da Comunicação de Crise. Sturges (1994) explicou, a este respeito, que a criação de opiniões positivas no espaço público e na comunidade interna da organização requer uma personalização do conteúdo das mensagens de acordo com a fase da crise e com o tipo de informação necessária e desejada pelos diferentes públicos, sendo que a primeira informação deve ser enviada ao público interno (Jouany, 2020). As práticas da UMinho terão resultado da urgência da comunicação ao espaço público, mas também da ausência de um gabinete de crise, de protocolos de gestão de crise e de um plano de comunicação de crise estabelecidos longitudinalmente na instituição.

\footnotetext{
7 https://www.uminho.pt/PT/viver/COVID-19
} 


\section{CONCLUSÕES}

A partir da análise realizada, conclui-se que as mensagens organizacionais e dos média podem ser alinhadas para reagir a crises e promover os melhores comportamentos de saúde. O alinhamento da comunicação entre as organizações e os média é considerado uma "boa prática" de Comunicação de Crise em saúde pública, com o objetivo de impedir o surgimento de mensagens dissonantes que possam questionar o comportamento social recomendado. No estudo de caso, percebemos que a necessária mudança do regime de trabalho na Universidade foi rápida e com grande aceitação por parte dos seus membros e da comunidade local. O surto de COVID-19 na Universidade foi controlado.

No entanto, não temos como inferir sistematicamente que a transformação comportamental resultou da qualidade da informação prestada pelos média, por via do seu alinhamento com a organização. Mas julgamos estar em condições de responder à nossa preocupação de partida, que questionava a relação entre o alinhamento comunicativo organizações públicas-média e a qualidade da informação prestada às populações, numa situação de crise de saúde pública.

Neste quadro, olhando para o caso em estudo, parece-nos que podemos reafirmar que o alinhamento é uma premissa importante na passagem de informação urgente e sensível às populações, mas, por outro lado, julgamos que não traz consigo necessariamente qualidade à informação. Para que essa qualidade exista, as fontes organizacionais precisam de se envolver na produção de mensagens adequadas ao interesse público (nesse contexto, seriam os despachos oficiais o melhor modelo de comunicado à imprensa?). E os média devem questionar e aprofundar os pacotes de informações que Ihes chegam (será a reprodução das declarações institucionais a melhor forma de notícia?).

No caso da UMinho, o seu desempenho não parece ter causado nenhum dano grave ao espaço público, pois a instituição agiu com responsabilidade. Mas certamente resultou em informação pública mais pobre, já que várias perguntas nunca foram respondidas: deveria a Universidade ter sido encerrada devido a um único caso de COVID-19? Os seus quase 20 mil estudantes deveriam ter sido mandados para casa? A pesquisa em laboratório deveria ter sido abandonada? O medo tomou conta da Universidade? Talvez as respostas a estas questões não mudassem a legitimidade das opções da instituição, mas estas teriam saído 
certamente mais reforçadas. Além de que deixar perguntas por responder não é algo que interesse ao Jornalismo, nem à Comunicação Estratégica, cujo trabalho deve estar sempre alinhado para o desenvolvimento de sociedades confiáveis, transparentes e inclusivas.

Face a estes resultados, fará, talvez, sentido evocar o conceito de Comunicação Pública, um campo que tem vindo a ser explorado para analisar o comportamento comunicativo de estados, governos ou instituições públicas, na defesa da construção de melhores relacionamentos entre o serviço público e a sociedade, assentes no valor da transparência para o exercício da cidadania (Duarte, 2011). E, neste quadro, não podemos deixar de reconhecer o papel dos média, enquanto vulgarizadores, transmissores e enriquecedores da informação colocada no espaço público. Reconhecendo que este processo se torna particularmente complexo em situações de crise, importa referir que é também em momentos de transformação que se exige maior responsabilidade para quem faz comunicação pública.

Para finalizar, refira-se que este trabalho apresenta vários tipos de limitações. Tratou-se de um estudo de caso único, aplicado pouco tempo depois da crise organizacional ter acontecido. Para que as nossas reflexões possam ter mais representatividade, será necessário aplicar o modelo de estudo a outros atores da sociedade e a outros meios de comunicação social, noutras fases da crise. Ainda assim julgamos que contribui para a reflexão sobre os processos de produção noticiosa em situações de crise de saúde pública.

\section{REFERÊNCIAS}

Atton, C., e Wickenden, E. (2005). Sourcing routines and representation in alternative journalism: A case study approach. Journalism studies, 6(3), 347-359.

Bardin, L. (2011). Análise de Conteúdo. São Paulo: Edições 70 - Almedina Brasil.

Brockway, R. (2018). Internal vs. External Crisis Communications. Retirado de https://hmapr.com/internal-vs-external-crisis-communications/

Calvo, A. (2017, 09 de junho). El Pais. Retirado de http://elpais.com/elpais/2017/06/08/ciencia/1496933982 127392.html?id externo rsoc =FB CC. 9 de junio del 2017 
Casero-Ripollés, A. (2020). Impact of Covid-19 on the media system. Communicative and democratic consequences of news consumption during the outbreak. El profesional de la información, 29(2), e290223

Coombs, W. T. (2007). Protecting Organization Reputations During a Crisis: The Development and Application of Situational Crisis Communication Theory. Corporate Reputation Review, 10(3), 163-176.

Coombs, W. T. (2010). Crisis Communication and Its Allied Fields. Em W. T. Coombs e S. J. Holladay (Eds.), The Handbook of Crisis Communication (pp. 54-64). United Kingdom: Wiley-Blackwell.

Coombs, W. T. (2015). The value of communication during a crisis: Insights from strategic communication research. Business Horizons, 58(2), 141-148.

Costa-Sánchez, C. e López-García, X. (2020). Comunicación y crisis del coronavirus en España. Primeras lecciones. El profesional de la información, 29(3), e290304.

Despacho RT-23/2020 de 7 de março da Universidade do Minho. Retirado de https://www.uminho.pt/PT/viver/COVID-19/Documents/Despacho RT 23-2020 PT.pdf Despacho RT-24/2020 de 8 de março da Universidade do Minho. Retirado de https://www.uminho.pt/PT/viver/COVID-19/Documents/Despacho RT 24-2020 PT.pdf Despacho RT-25/2020 de 10 de março da Universidade do Minho. Retirado de https://www.uminho.pt/PT/viver/COVID-19/Documents/Despacho RT 25-2020 PT.pdf

Duarte, J. (2011). Sobre a emergência do(s) conceito(s) de comunicação pública. In M. Kunsch (Ed.), Comunicação pública, sociedade e cidadania (pp.121-134). São Caetano do Sul: Difusão Editora.

Freimuth, V. e Quinn, S. (2004). The Contributions of Health Communication to Eliminating Health Disparities. American Journal of Public Health, 24(12), 2053-2055.

Gomes, S. (2019). Jornalismo e prevenção em saúde: retratos da imprensa portuguesa entre 2012 e 2014. Tese de Doutoramento, Universidade do Minho, Braga. 
Hallahan, K., Holtzhausen, D., Van Ruler, B., Verčič, D., e Sriramesh, K. (2007). Defining strategic communication. International journal of strategic communication, 1(1), 3-35.

Hermann, C. (1963). Some Consequences of Crisis Which Limit the Viability of Organizations. Administrative Science Quarterly, 8(1), 61-82.

Holladay, S. (2009). Crisis Communication Strategies in the Media Coverage of Chemical Accidents. Journal of Public Relations Research, 21(1), 208-217.

Jouany, V. (2020). Crisis Communication - How to Communicate Effectively with Your Employees. Retirado de https://blog.smarp.com/crisis-communication-how-tocommunicate-with-employees-during-a-crisis

Knight, M. (2020). Pandemic Communication: A New Challenge for Higher Education. Business and Professional Communication Quarterly, 83(2), 131-132.

Kovach, B. e Rosenstiel, T. (2003). The elements of journalism. Londres: Atlantic Books. Kovach, B. e Rosenstiel, T. (2007). The elements of journalism: What newspeople should know and the public should expect. New York: Three Rivers Press.

Kreps, G. e Thornton, B. (1984). Health communication. Nova lorque: Longman Inc. Lacy, S., e Rosenstiel, T. (2015). Defining and measuring quality journalism. Rutgers School of Communication and Information.

Lázaro-Rodríguez, P. e Herrera-Viedma, E. (2020). Noticias sobre Covid-19 y 2019-nCoV en medios de comunicación de España: el papel de los medios digitales en tiempos de confinamiento. El profesional de la información, 29(3), e290302.

Local Government Association. (2020). Internal communications during times of crisis. Retirado de https://www.local.gov.uk/our-support/guidance-and-resources/comms-hubcommunications-support/internal-communications-3

Lopes, F. (2007). A TV das elites. Porto: Campo das Letras. 
Lopes, F.; Ruão, T., Marinho, S. e Araújo, R. (2012). A saúde em notícia entre 2008 e 2010 : retratos do que a imprensa portuguesa mostrou. Comunicação e Sociedade [número especial], 129-170. doi: 10.17231/comsoc.23(2012).1361

Lopes, F., Ruão, T., e Marinho, S. (2010). Gripe A na Imprensa Portuguesa: uma doença em notícia através de uma organizada estratégia de comunicação. Observatorio (OBS*), 4(4).

Lopes, F., Ruão, T., Marinho, S. e Araújo, R. (2011a). Jornalismo de saúde e fontes de informação, uma análise dos jornais portugueses entre 2008 e 2010. Derecho a Comunicar, $2,100-200$.

Lopes, F., Ruão, T., Marinho, S. e Araújo, R. (2011b). Escherichia coli: a disease in the news, Journal of Management \& Marketing in Healthcare, 6(1), 51-62.

McQuail, D. (2003). Teoria da Comunicação de Massas. Lisboa: Fundação Calouste Gulbenkien.

Martins, M. (2010). Prefácio: Jornalismo e sonho de comunidade. Em M. Oliveira Metajornalismo. Quando o jornalismo é sujeito do próprio discurso (pp. 9-13). Coimbra: Grácio Editor.

Mena-Young, M. (2020). La narrativa pública en salud: análisis de grandes reportajes sobre el ébola. Revista Linguagem \& Ensino, 23(1), 260-279.

Northouse P. e Northouse, L. (1985). Health communication: a handbook for health professionals. Nova Jersey: Prentice Hall.

Obregón, J. (1998). Especialización, futuro del periodismo. Revista Latina de Comunicación Social, 7.

Ray, S. J. (1999). Strategic communication in crisis management: Lessons from the airline industry. Westport, CT: Quorum.

Reynolds, B. e Seeger, M. W. (2005). Crisis and Emergency Risk Communication as an Integrative Model. Journal of Health Communication, 10(1), 43-55. 
Ruão, T. (2008). A Comunicação Organizacional e os Fenómenos de Identidade: a aventura comunicativa da formação da Universidade do Minho, 1974-2006. (Tese de Doutoramento em Ciências da Comunicação), Universidade do Minho, Braga.

Ruão, T., Lopes, F., Marinho, S. e Araújo, R. (2011). Media relations and health news coverage: the dialogue on Influenza A in Portugal. Em G. Gonçalves (Ed.), The dialogue imperative, trends and challenges in strategic and organisational communication (pp. 6380). Covilhã: Livros Labcom.

Schreier, M. (2012). Qualitative Content Analysis in Practice. Londres: Sage Publications Schwitzer, G. (2009). Seven words (and more) you shouldn't use in medical news. Retirado de http://www.healthnewsreview.org/toolkit/tips-for-understanding-studies/7-wordsand-more-you-shouldnt-use-in-medical-news/

Selznick, Philip (1996). "Institutionalism 'old' and 'new' “, Administrative Science Quarterly, 41(2), 270-277.

Sharf, B. (1984). The physician's guide to better communication. Glenview: Scott, Foresman.

Sturges, D. L. (1994). Communicating through crisis: A strategy for organizational survival. Management Communication Quarterly, 7, 297-316.

Thomas, K. e Senkpeni, A. (2020). What Should Health Science Journalists Do in Epidemic Responses? AMA Journal of Ethics, 22(1), 55-60.

Valero-Cedeño, N. J., Mina-Ortiz, J. B., Veliz-Castro, T. I., Merchán-Villafuerte, K. M., e Perozo-Mena, A. J. (2020). COVID-19: La nueva pandemia con muchas lecciones y nuevos retos. Revisión Narrativa. Kasmera, 48(1).

Vaughan, E. e Tinker, T. (2009). Effective health risk communication about pandemic influenza for vulnerable populations. American Journal of Public Health, 99(2), 324-332.

Vos, S. C. e Buckner, M. M. (2016). Social Media Messages in an Emerging Health Crisis: Tweeting Bird Flu. Journal of Health Communication, 31, 301-308. 
Walter, J., Kellermanns, F. W., Floyd, S. W., Veiga, J. F., e Matherne, C. (2013). Strategic alignment: A missing link in the relationship between strategic consensus and organizational performance. Strategic Organization, 11(3), 304-328.

White, D. M. (1950). The gatekeeper: a case-study in the selection of news. Journalism \& Mass Communication Quarterly, 27(4), 383-90.

Wilson, A., Robertson, J., McElduff, P., Jones, A. e Henry, D. (2010). Does it matter who writes medical news stories? PLoS Med, 7(9), e1000323.

Yin, R. K. (2014). Case study research: design and methods (5 ed.). Thousand Oaks: Sage Publications. 